\title{
Strong Convergence Theorem for Solving Generalized Mixed Equilibrium Problems and Fixed Point Problems for Total Quasi- $\phi$-Asymptotically Nonexpansive Mappings in Banach Spaces
}

\author{
Zhaoli Ma, ${ }^{1}$ Lin Wang, ${ }^{2}$ and Yunhe Zhao ${ }^{2}$ \\ ${ }^{1}$ School of Information Engineering, The College of Arts and Sciences, Yunnan Normal University, \\ Kunming, Yunnan 650222, China \\ ${ }^{2}$ College of Statistics and Mathematics, Yunnan University of Finance and Economics, Kunming, \\ Yunnan 650221, China
}

Correspondence should be addressed to Lin Wang,w164mail@yahoo.com.cn

Received 9 February 2012; Accepted 10 April 2012

Academic Editor: Morteza Rafei

Copyright (C) 2012 Zhaoli Ma et al. This is an open access article distributed under the Creative Commons Attribution License, which permits unrestricted use, distribution, and reproduction in any medium, provided the original work is properly cited.

We introduce an iterative scheme for finding a common element of the set of solutions of generalized mixed equilibrium problems and the set of fixed points for countable families of total quasi- $\phi$ asymptotically nonexpansive mappings in Banach spaces. We prove a strong convergence theorem of the iterative sequence generated by the proposed iterative algorithm in an uniformly smooth and strictly convex Banach space which also enjoys the Kadec-Klee property. The results presented in this paper improve and extend some recent corresponding results.

\section{Introduction}

Let $E$ be a real Banach space with the dual $E^{*}$ and let $C$ be a nonempty closed convex subset of $E$. We denote by $R^{+}$and $R$ the set of all nonnegative real numbers and the set of all real numbers, respectively. Also, we denote by $J$ the normalized duality mapping from $E$ to $2^{E^{*}}$ defined by

$$
J x=\left\{x^{*} \in E^{*}:\left\langle x, x^{*}\right\rangle=\|x\|^{2}=\left\|x^{*}\right\|^{2}\right\}, \quad \forall x \in E,
$$

where $\langle\cdot, \cdot\rangle$ denotes the generalized duality pairing. Recall that if $E$ is smooth then $J$ is singlevalued and norm-to-weak* continuous, and that if $E$ is uniformly smooth then $J$ is uniformly 
norm-to-norm continuous on bounded subsets of $E$. We will denote by $J$ the single-value duality mapping.

A Banach space $E$ is said to be strictly convex if $\|x+y\| / 2 \leq 1$ for all $x, y \in U=\{z \in E$ : $\|z\|=1\}$ with $x \neq y$. $E$ is said to be uniformly convex if, for each $\varepsilon \in(0,2]$, there exists $\delta>0$ such that $\|x+y\| / 2 \leq 1-\delta$ for all $x, y \in U$ with $\|x-y\| \geq \varepsilon$. $E$ is said to be smooth if the limit

$$
\lim _{t \rightarrow 0} \frac{\|x+t y\|-\|x\|}{t}
$$

exists for all $x, y \in U$. $E$ is said to be uniformly smooth if the above limit exists uniformly in $x, y \in U$.

Remark 1.1. The following basic properties of Banach space $E$ can be founded in [1].

(i) If $E$ is an uniformly smooth Banach space, then $J$ is uniformly continuous on each bounded subset of $E$.

(ii) If $E$ is a reflexive and strictly convex Banach space, then $J^{-1}$ is norm-weak*-continuous.

(iii) If $E$ is a smooth, reflexive and strictly convex Banach space, then the normalized duality mapping $J: E \rightarrow 2^{E^{*}}$ is single-valued, one-to-one, and surjective.

(iv) A Banach space $E$ is uniformly smooth if and only if $E^{*}$ is uniformly convex.

(v) Each uniformly convex Banach space $E$ has the Kadec-Klee property, that is, for any sequence $\left\{x_{n}\right\} \subset E$, if $x_{n} \rightarrow x \in E$ and $\left\|x_{n}\right\| \rightarrow\|x\|$, then $x_{n} \rightarrow x$. (See [1,2]) for more details.

Next, we assume that $E$ is a smooth, reflexive, and strictly convex Banach space. Consider the functional defined as in $[3,4]$ by

$$
\phi(x, y)=\|x\|^{2}-2\langle x, J y\rangle+\|y\|^{2}, \quad \forall x, y \in E
$$

It is clear that in a Hilbert space $H,(1.3)$ reduces to $\phi(x, y)=\|x-y\|^{2}$, for all $x, y \in H$.

It is obvious from the definition of $\phi$ that

$$
(\|x\|-\|y\|)^{2} \leq \phi(x, y) \leq(\|x\|+\|y\|)^{2}, \quad \forall x, y \in E,
$$

and

$$
\phi\left(x, J^{-1}(\lambda J y+(1-\lambda) J z)\right) \leq \lambda \phi(x, y)+(1-\lambda) \phi(x, z), \quad \forall x, y \in E .
$$

Following Alber [3], the generalized projection $\Pi_{C}: E \rightarrow C$ is defined by

$$
\Pi_{C}(x)=\operatorname{arginf}_{y \in C} \phi(y, x), \quad \forall x \in E .
$$

That is, $\Pi_{C} x=\bar{x}$, where $\bar{x}$ is the unique solution to the minimization problem $\phi(\bar{x}, x)=$ $\inf _{y \in C} \phi(y, x)$. 
The existence and uniqueness of the operator $\Pi_{C}$ follows from the properties of the functional $\phi(x, y)$ and strict monotonicity of the mapping $J$ (see, e.g., [1-5]). In Hilbert space $H, \Pi_{C}=P_{C}$.

Let $C$ be a nonempty closed convex subset of $E$, let $T$ be a mapping from $C$ into itself, and let $F(T)$ be the set of fixed points of $T$. A point $p \in C$ is called an asymptotically fixed point of $T[6]$ if there exists a sequence $\left\{x_{n}\right\} \subset C$ such that $x_{n} \rightarrow p$ and $\left\|x_{n}-T x_{n}\right\| \rightarrow 0$. The set of asymptotical fixed points of $T$ will be denoted by $\widehat{F}(T)$. A point $p \in C$ is said to be a strong asymptotic fixed point of $T$, if there exists a sequence $\left\{x_{n}\right\} \subset C$ such that $x_{n} \rightarrow p$ and $\left\|x_{n}-T x_{n}\right\| \rightarrow 0$. The set of strong asymptotical fixed points of $T$ will be denoted by $\widetilde{F}(T)$.

A mapping $T: C \rightarrow C$ is said to be relatively nonexpansive [7-9], if $F(T) \neq \emptyset, F(T)=$ $\widehat{F}(T)$ and $\phi(p, T x) \leq \phi(p, x)$, for all $x \in C, p \in F(T)$.

A mapping $T: C \rightarrow C$ is said to be quasi- $\phi$-nonexpansive, if $F(T) \neq \emptyset$ and $\phi(p, T x) \leq$ $\phi(p, x)$, for all $x \in C, p \in F(T)$.

A mapping $T: C \rightarrow C$ is said to be quasi- $\phi$-asymptotically nonexpansive, if $F(T) \neq \emptyset$ and there exists a real sequence $\left\{k_{n}\right\} \subset[1, \infty)$ with $k_{n} \rightarrow 1$ such that

$$
\phi\left(p, T^{n} x\right) \leq k_{n} \phi(p, x), \quad \forall n \geq 1, x \in C, p \in F(T)
$$

A mapping $T: C \rightarrow C$ is said to be total quasi- $\phi$-asymptotically nonexpansive, if $F(T) \neq \emptyset$ and there exists nonnegative real sequences $\left\{v_{n}\right\},\left\{\mu_{n}\right\}$ with $v_{n} \rightarrow 0, \mu_{n} \rightarrow 0$ (as $n \rightarrow \infty$ ) and a strictly increasing continuous function $\xi: R^{+} \rightarrow R^{+}$with $\xi(0)=0$ such that

$$
\phi\left(p, T^{n} x\right) \leq \phi(p, x)+v_{n} \xi(\phi(p, x))+\mu_{n}, \quad \forall n \geq 1, x \in C, p \in F(T)
$$

A countable family of mappings $\left\{T_{n}\right\}: C \rightarrow C$ is said to be uniformly total quasi- $\phi$ asymptotically nonexpansive, if $\bigcap_{i=1}^{\infty} F\left(T_{i}\right) \neq \emptyset$, and there exists nonnegative real sequences $\left\{v_{n}\right\},\left\{\mu_{n}\right\}$ with $v_{n} \rightarrow 0, \mu_{n} \rightarrow 0$ (as $\left.n \rightarrow \infty\right)$ and a strictly increasing continuous function $\xi: R^{+} \rightarrow R^{+}$with $\xi(0)=0$ such that for each $i \geq 1$ and each $x \in C, p \in \bigcap_{i=1}^{\infty} F\left(T_{i}\right)$

$$
\phi\left(p, T_{i}^{n} x\right) \leq \phi(p, x)+v_{n} \xi(\phi(p, x))+\mu_{n}, \quad \forall n \geq 1
$$

Remark 1.2. From the definition, it is easy to know that:

(i) each relatively nonexpansive mapping is closed;

(ii) taking $\xi(t)=t, t \geq 0, v_{n}=\left(k_{n}-1\right)$ and $\mu_{n}=0$ then $v_{n} \rightarrow 0$ (as $\left.n \rightarrow \infty\right)$ and (1.7) can be rewritten as

$$
\phi\left(p, T^{n} x\right) \leq \phi(p, x)+v_{n} \xi(\phi(p, x))+\mu_{n}, \quad \forall n \geq 1, x \in C, p \in F(T)
$$

this implies that each quasi- $\phi$-asymptotically nonexpansive mapping must be a total quasi- $\phi$-asymptotically nonexpansive mapping, but the converse is not true;

(iii) the class of quasi- $\phi$-asymptotically nonexpansive mappings contains properly the class of quasi- $\phi$-nonexpansive mappings as a subclass, but the converse is not true; 
(iv) the class of quasi- $\phi$-nonexpansive mappings contains properly the class of relatively nonexpansive mappings as a subclass, but the converse may be not true. (See more details [10-14]).

Let $f: C \times C \rightarrow R$ be a bifunction, where $R$ is the set of real numbers. The equilibrium problem (For short, EP) is to find $x^{*} \in C$ such that

$$
f\left(x^{*}, y\right) \geq 0, \quad \forall y \in C
$$

The set of solutions of EP (1.11) is denoted by $\mathrm{EP}(f)$.

Let $B: C \rightarrow H$ be a nonlinear mapping. The generalized equilibrium problem (for short, GEP) is to find $x^{*} \in C$ such that

$$
f\left(x^{*}, y\right)+\left\langle B x^{*}, y-x^{*}\right\rangle \geq 0, \quad \forall y \in C
$$

The set of solutions of GEP (1.12) is denoted by $\operatorname{GEP}(f, B)$, that is,

$$
\operatorname{GEP}(f, B)=\left\{x^{*} \in C: f\left(x^{*}, y\right)+\left\langle B x^{*}, y-x^{*}\right\rangle \geq 0, \quad \forall y \in C\right\}
$$

Let $\varphi: C \rightarrow R \cup\{+\infty\}$ be a function. The mixed equilibrium problem (for short, MEP) is to find $x^{*} \in C$ such that

$$
f\left(x^{*}, y\right)+\varphi(y)-\varphi\left(x^{*}\right) \geq 0, \quad \forall y \in C
$$

The set of solutions of MEP (1.14) is denoted by $\operatorname{MEP}(f)$.

The concept generalized mixed equilibrium problem (for short, GMEP) was introduced by Peng and Yao [15] in 2008. GMEP is to find $x^{*} \in C$ such that

$$
f\left(x^{*}, y\right)+\varphi(y)-\varphi\left(x^{*}\right)+\left\langle B x^{*}, y-x^{*}\right\rangle \geq 0, \quad \forall y \in C
$$

The set of solutions of GMEP (1.15) is denoted by $\operatorname{GMEP}(f, B, \varphi)$, that is,

$$
\operatorname{GMEP}(f, B, \varphi)=\left\{x^{*} \in C: f\left(x^{*}, y\right)+\varphi(y)-\varphi\left(x^{*}\right)+\left\langle B x^{*}, y-x^{*}\right\rangle \geq 0, \quad \forall y \in C\right\}
$$

The equilibrium problem is an unifying model for several problems arising in physics, engineering, science optimization, economics, transportation, network and structural analysis, Nash equilibrium problems in noncooperative games, and others. It has been shown that variational inequalities and mathematical programming problems can be viewed as a special realization of the abstract equilibrium problems (e. g., [16, 17]). Many authors have proposed some useful methods to solve the EP, GEP, MEP, GMEP; see, for instance, [15-23] and the references therein. 
In 2005, Matsushita and Takahashi [13] proposed the following hybrid iteration method (it is also called the CQ method) with generalized projection for relatively nonexpansive mapping $T$ in a Banach space $E$ :

$$
\begin{gathered}
x_{0} \in C \text { chosen arbitrary, } \\
y_{n}=J^{-1}\left(\alpha_{n} J x_{n}+\left(1-\alpha_{n}\right) J x_{n}\right), \\
C_{n}=\left\{z \in C: \phi\left(z, y_{n}\right) \leq \phi\left(z, x_{n}\right)\right\}, \\
Q_{n}=\left\{z \in C:\left\langle x_{n}-z, J x_{0}-J x_{n}\right\rangle \geq 0\right\}, \\
x_{n+1}=\prod_{C_{n} \cap Q_{n}} x_{0}, \quad n \geq 0 .
\end{gathered}
$$

They prove that $\left\{x_{n}\right\}$ converges strongly to $\Pi_{F(T)} x_{0}$, where $\Pi_{F(T)}$ is the generalized projection from $C$ onto $F(T)$.

Recently, Qin et al. [24] proposed a shrinking projection method to find a common element of the set of solutions of an equilibrium problem and the set of common fixed points of a finite family of quasi- $\phi$-nonexpansive mappings in the framework of Banach spaces:

$$
\begin{gathered}
x_{0}=x \text { chosen arbitrary, } \\
C_{1}=C \\
x_{1}=\Pi_{C_{1}} x_{0}, \\
y_{n}=J^{-1}\left(\alpha_{n, 0} J x_{n}+\sum_{i=1}^{N} \alpha_{n, i} J T_{i} x_{n}\right), \\
u_{n} \in C \text { such that } f\left(u_{n}, y\right)+\frac{1}{r_{n}}\left\langle y-u_{n}, J u_{n}-J y_{n}\right\rangle \geq 0, \quad \forall y \in C, \\
C_{n+1}=\left\{z \in C_{n}: \phi\left(z, u_{n}\right) \leq \phi\left(z, x_{n}\right)\right\}, \\
x_{n+1}=\prod_{C_{n+1}} x_{0}, \quad n \geq 0,
\end{gathered}
$$

where $\Pi_{C_{n+1}}$ is the generalized projection from $E$ onto $C_{n+1}$. They prove that the sequence $\left\{x_{n}\right\}$ converges strongly to $\prod_{\cap_{i=1}^{N} F\left(T_{i}\right) \cap E P(f)} x_{0}$.

In [25], Saewan and Kumam introduced a modified new hybrid projection method to find a common element of the set of solutions of the generalized mixed equilibrium problems and the set of common fixed points of an infinite family of closed and uniformly quasi- $\phi$ asymptotically nonexpansive mappings in an uniformly smooth and strictly convex Banach 
spaces $E$ with Kadec-Klee property:

$$
\begin{gathered}
x_{0} \in C \text { chosen arbitrary, } \\
x_{1}=\Pi_{C_{1}} x_{0}, \\
C_{1}=C, \\
y_{n}=J^{-1}\left(\alpha_{n} J x_{n}+\left(1-\alpha_{n}\right) J z_{n}\right), \\
z_{n}=J^{-1}\left(\beta_{n, 0} J x_{n}+\sum_{i=1}^{\infty} \beta_{n, i} J T_{i}^{n} x_{n}\right), \\
u_{n} \in C \text { such that } u_{n}=K_{r_{n}} y_{n}, \\
C_{n+1}=\left\{z \in C_{n}: \phi\left(z, u_{n}\right) \leq \phi\left(z, x_{n}\right)+\xi_{n}\right\}, \\
x_{n+1}=\Pi_{C_{n+1}} x_{0}, \quad n \geq 0,
\end{gathered}
$$

where $\xi_{n}=\sup _{p \in F}\left(k_{n}-1\right) \phi\left(p, x_{n}\right), \Pi_{C_{n+1}}$ is the generalized projection of $E$ onto $C_{n+1}$. They prove that the sequence $\left\{x_{n}\right\}$ converges strongly to $\prod_{\bigcap_{i=1}^{\infty} F\left(T_{i}\right) \cap \operatorname{GMEP}(f)} x_{0}$.

Very recently, Chang et al. [26] proposed the following iterative algorithm for solving fixed point problems for total quasi- $\phi$-asymptotically nonexpansive mappings:

$$
\begin{gathered}
x_{0} \in C \text { chosen arbitrary, } C_{0}=C, \\
y_{n}=J^{-1}\left(\alpha_{n} J x_{n}+\left(1-\alpha_{n}\right) J z_{n}\right), \\
z_{n}=J^{-1}\left(\beta_{n, 0} J x_{n}+\sum_{i=1}^{\infty} \beta_{n, i} J T_{i}^{n} x_{n}\right), \\
C_{n+1}=\left\{z \in C_{n}: \phi\left(v, y_{n}\right) \leq \phi\left(v, x_{n}\right)+\xi_{n}\right\}, \\
x_{n+1}=\prod_{C_{n+1}} x_{0}, \quad n \geq 0,
\end{gathered}
$$

where $\xi_{n}=v_{n} \sup _{p \in F} \xi\left(\phi\left(p, x_{n}\right)\right)+\mu_{n}, \Pi_{C_{n+1}}$ is the generalized projection of $E$ onto $C_{n+1}$. They prove that the sequence $\left\{x_{n}\right\}$ converges strongly to $\prod_{\bigcap_{i=1}^{\infty} F\left(T_{i}\right)} x_{0}$.

Inspired and motivated by the recent work of Matsushita and Takahashi [13], Qin et al. [24], Saewan and Kumam [25], Chang et al. [26], and so forth, we introduce an iterative scheme for finding a common element of the set of solutions of generalized mixed equilibrium problems and the set of fixed points of a countable families of total quasi- $\phi$-asymptotically nonexpansive mappings in Banach spaces. We prove a strong convergence theorem of the iterative sequence generated by the proposed iterative algorithm in an uniformly smooth and strictly convex Banach space which also enjoys the Kadec-Klee property. The results presented in this paper improve and extend some recent corresponding results in [13, 24-29]. 


\section{Preliminaries}

Throughout this paper, let $E$ be a real Banach space with the dual $E^{*}$ and let $C$ be a nonempty closed convex subset of $E$. We denote the strong convergence, weak convergence of a sequence $\left\{x_{n}\right\}$ to a point $x \in E$ by $x_{n} \rightarrow x, x_{n} \rightarrow x$, respectively, and $F(T)$ is the fixed point set of a mapping $T$.

In this paper, for solving generalized mixed equilibrium problems, we assume that bifunction $f: C \times C \rightarrow R$ satisfies the following conditions:

(A1) $f(x, x)=0$, for all $x \in C$;

(A2) $f(x, y)+f(y, x) \leq 0$, for all $x, y \in C$;

(A3) for all $x, y, z \in C, \lim _{t \downarrow} f(t z+(1-t) x, y) \leq f(x, y)$;

(A4) for each $x \in C$, the function $y \longmapsto f(x, y)$ is convex and lower semicontinuous.

Lemma 2.1 (see [16]). Let $C$ be a nonempty closed convex subset of a smooth, strictly convex, and reflexive Banach space $E$, let $f$ be a bifunction from $C \times C$ to $R$ satisfying $(A 1)-(A 4)$, and let $r>0$ and $x \in E$, then there exists $z \in C$ such that

$$
f(z, y)+\frac{1}{r}\langle y-z, J z-J x\rangle \geq 0, \quad \forall y \in C
$$

Lemma 2.2 (see [30]). Let $C$ be a nonempty closed convex subset of a smooth, strictly convex, and reflexive Banach space $E$. Let $B: C \rightarrow E^{*}$ be a continuous and monotone mapping, let $\varphi: C \rightarrow R$ be convex and lower semicontinuous and let $f$ be a bifunction from $C \times C$ to $R$ satisfying $(A 1)-(A 4)$. For $r>0$ and $x \in E$, then there exists $u \in C$ such that

$$
f(u, y)+\varphi(y)-\varphi(u)+\langle B u, y-u\rangle+\frac{1}{r}\langle y-u, J u-J x\rangle \geq 0, \quad \forall y \in C .
$$

Define a mapping $K_{r}: C \rightarrow C$ as follows:

$$
K_{r}(x)=\left\{u \in C: f(u, y)+\varphi(y)-\varphi(u)+\langle B u, y-u\rangle+\frac{1}{r}\langle y-u, J u-J x\rangle \geq 0, \quad \forall y \in C\right\}
$$

for all $x \in C$. Then, the following hold:

(1) $K_{r}$ is single-valued;

(2) $K_{r}$ is firmly nonexpansive, that is, for all $x, y \in E$,

$$
\left\langle K_{r} x-K_{r} y, J K_{r} x-J K_{r} y\right\rangle \leq\left\langle K_{r} x-K_{r} y, J x-J y\right\rangle
$$

(3) $F\left(K_{r}\right)=\operatorname{GMEP}(f, B, \varphi)$;

(4) $\operatorname{GMEP}(f, B, \varphi)$ is closed and convex;

(5) $\phi\left(p, K_{r} z\right)+\phi\left(K_{r} z, z\right) \leq \phi(p, z)$, for all $p \in F\left(K_{r}\right)$ and $z \in E$. 
Lemma 2.3 (see [28]). Let E be a real uniformly smooth and strictly convex Banach space with Kadec-Klee property and let $C$ be a nonempty closed convex subset of $E$. Let $\left\{x_{n}\right\}$ and $\left\{y_{n}\right\}$ be two sequences in $C$ such that $x_{n} \rightarrow p$ and $\phi\left(x_{n}, y_{n}\right) \rightarrow 0$, where $\phi$ is the function defined by (1.3), then $y_{n} \rightarrow p$.

Lemma 2.4 (see [3]). Let E be a smooth, strictly convex and reflexive Banach space and let $C$ be a nonempty closed convex subset of $E$. Then, the following conclusions hold:

(a) $\phi\left(x, \Pi_{C} y\right)+\phi\left(\Pi_{C} y, y\right) \leq \phi(x, y)$, for all $x \in C, y \in E$;

(b) if $x \in E$ and $z \in C$, then $z=\Pi_{C} x$ if and only if $\langle z-y, J x-J z\rangle \geq 0$, for all $y \in C$;

(c) for $x, y \in E, \phi(x, y)=0$ if and only if $x=y$.

Lemma 2.5 (see [28]). Let E be a real uniformly smooth and strictly convex Banach space with Kadec-Klee property and let $C$ be a nonempty closed convex subset of $E$. Let $T: C \rightarrow C$ be a closed and total quasi- $\phi$-asymptotically nonexpansive mapping with nonnegative real sequences $\left\{v_{n}\right\},\left\{\mu_{n}\right\}$, and a strictly increasing continuous functions $\xi: R^{+} \rightarrow R^{+}$such that $v_{n} \rightarrow 0, \mu_{n} \rightarrow 0$ (as $n \rightarrow \infty$ ) and $\xi(0)=0$. If $\mu_{1}=0$, then the fixed point set $F(T)$ of $T$ is a closed and convex subset of $C$.

Lemma 2.6 (see [31]). Let $E$ be an uniformly convex Banach space, let $r$ be a positive number, and let $B_{r}(0)$ be a closed ball of $E$. Then, for any sequence $\left\{x_{i}\right\}_{i=1}^{\infty} \subset B_{r}(0)$ and for any sequence $\left\{\lambda_{i}\right\}_{i=1}^{\infty}$ of positive numbers with $\sum_{n=1}^{\infty} \lambda_{n}=1$, there exists a continuous, strictly increasing, and convex function $g:[0,2 r] \rightarrow[0, \infty), g(0)=0$ such that, for any positive integer $i \neq 1$, the following holds:

$$
\left\|\sum_{n=1}^{\infty} \lambda_{n} x_{n}\right\|^{2} \leq \sum_{n=1}^{\infty} \lambda_{n}\left\|x_{n}\right\|^{2}-\lambda_{1} \lambda_{i} g\left(\left\|x_{1}-x_{i}\right\|\right) .
$$

\section{Main Results}

Theorem 3.1. Let $C$ be a nonempty, closed, and convex subset of an uniformly smooth and strictly convex Banach Banach space $E$ with Kadec-Klee property. Let $B: C \rightarrow E^{*}$ be a continuous and monotone mapping and let $\varphi: C \rightarrow R$ be a lower semicontinuous and convex function. Let $f$ be a bifunction from $C \times C$ to $R$ satisfying (A1)-(A4). Let $\left\{T_{i}\right\}_{i=1}^{\infty}: C \rightarrow C$ be a countable family of closed and uniformly total quasi- $\phi$-asymptotically nonexpansive mappings with nonnegative real sequences $\left\{v_{n}\right\},\left\{\mu_{n}\right\}$ and a strictly increasing continuous function $\zeta: R^{+} \rightarrow R^{+}$such that $\mu_{1}=0, v_{n} \rightarrow 0$, $\mu_{n} \rightarrow 0$ (as $\left.n \rightarrow \infty\right)$, and $\zeta(0)=0$, and for each $i \geq 1, T_{i}$ is uniformly $L_{i}$-Lipschitz continuous. $\left\{x_{n}\right\}$ is defined by

$$
\begin{gathered}
x_{0} \in C \text { chosen arbitrary, } C_{0}=C, \\
y_{n}=J^{-1}\left(\alpha_{n} J x_{n}+\left(1-\alpha_{n}\right) J z_{n}\right), \\
z_{n}=J^{-1}\left(\beta_{n, 0} J x_{n}+\sum_{i=1}^{\infty} \beta_{n, i} J T_{i}^{n} x_{n}\right),
\end{gathered}
$$


Journal of Applied Mathematics

$$
\begin{gathered}
u_{n} \in C \text { such that } u_{n}=K_{r_{n}} y_{n}, \\
C_{n+1}=\left\{v \in C_{n}: \phi\left(v, u_{n}\right) \leq \phi\left(v, x_{n}\right)+\xi_{n}\right\}, \\
x_{n+1}=\prod_{C_{n+1}} x_{0}, \quad n \geq 0,
\end{gathered}
$$

where $\xi_{n}=v_{n} \sup _{q \in \Theta} \zeta\left(\phi\left(q, x_{n}\right)\right)+\mu_{n}, \Pi_{C_{n+1}}$ is the generalized projection of $E$ onto $C_{n+1},\left\{r_{n}\right\} \subset$ $[a, \infty)$ for some $a>0,\left\{\beta_{n, 0}, \beta_{n, i}\right\}$ and $\left\{\alpha_{n}\right\}$ are sequences in $[0,1]$ satisfying the following conditions:

(1) for each $n \geq 0, \beta_{n, 0}+\sum_{i=1}^{\infty} \beta_{n, i}=1$;

(2) $\liminf _{n \rightarrow \infty} \beta_{n, 0} \beta_{n, i}>0$ for any $i \geq 1$;

(3) $0 \leq \alpha_{n} \leq \alpha<1$ for some $\alpha \in(0,1)$.

If $\Theta:=\bigcap_{i=1}^{\infty} F\left(T_{i}\right) \cap \operatorname{GMEP}(f, B, \varphi)$ is a nonempty and bounded subset in $C$, then the sequence $\left\{x_{n}\right\}$ converges strongly to $p \in F$, where $p=\prod_{\Theta} x_{0}$.

Proof. We will divide the proof into seven steps.

Step 1. We first show that $\Theta$ and $C_{n}$ are closed and convex for each $n \geq 0$.

It follows from Lemma 2.5 that $F\left(T_{i}\right)$ is closed and convex subset of $C$ for each $i \geq 1$. Therefore, $\Theta$ is closed and convex in $C$.

Again by the assumption, $C_{0}=C$ is closed and convex. Suppose that $C_{n}$ is closed and convex for some $n \geq 1$. Since for any $z \in C_{n}$, we know that

$$
\phi\left(z, u_{n}\right) \leq \phi\left(z, x_{n}\right)+\xi_{n} \Longleftrightarrow 2\left\langle z, J x_{n}-J u_{n}\right\rangle \leq\left\|x_{n}\right\|^{2}-\left\|u_{n}\right\|^{2}+\xi_{n} .
$$

Hence, the set $C_{n+1}=\left\{z \in C_{n}: 2\left\langle z, J x_{n}-J u_{n}\right\rangle \leq\left\|x_{n}\right\|^{2}-\left\|u_{n}\right\|^{2}+\xi_{n}\right\}$ is closed and convex. Therefore, $\Pi_{C_{n}} x_{0}$ and $\Pi_{\Theta} x_{0}$ are well defined.

Step 2. We show that $\Theta \subset C_{n}$ for all $n \geq 0$.

It is obvious that $\Theta \subset C_{0}=C$. Suppose that $\Theta \subset C_{n}$ for some $n \geq 1$. Since $E$ is uniformly smooth, $E^{*}$ is uniformly convex. By the convexity of $\|\cdot\|^{2}$, property of $\phi$, for any given $q \in$ $\Theta \subset C_{n}$, we observe that

$$
\begin{aligned}
\phi\left(q, u_{n}\right) & =\phi\left(q, K_{r_{n}} y_{n}\right) \\
& \leq \phi\left(q, y_{n}\right) \\
& =\phi\left(q, J^{-1}\left(\alpha_{n} J x_{n}+\left(1-\alpha_{n}\right) J z_{n}\right)\right) . \\
& =\|q\|^{2}-2\left\langle q, \alpha_{n} J x_{n}+\left(1-\alpha_{n}\right) J z_{n}\right\rangle+\left\|\alpha_{n} J x_{n}+\left(1-\alpha_{n}\right) J z_{n}\right\|^{2} \\
& \leq\|q\|^{2}-2 \alpha_{n}\left\langle q, J x_{n}\right\rangle-2\left(1-\alpha_{n}\right)\left\langle q, J z_{n}\right\rangle+\alpha_{n}\left\|x_{n}\right\|^{2}+\left(1-\alpha_{n}\right)\left\|z_{n}\right\|^{2} \\
& =\alpha_{n} \phi\left(q, x_{n}\right)+\left(1-\alpha_{n}\right) \phi\left(q, z_{n}\right) .
\end{aligned}
$$


Furthermore, it follows from Lemma 2.6 that, for any positive integers $l>1$ and for any $q \in \Theta$, we have

$$
\begin{aligned}
\phi\left(q, z_{n}\right)= & \phi\left(q, J^{-1}\left(\beta_{n, 0} J x_{n}+\sum_{i=1}^{\infty} \beta_{n, i} J T_{i}^{n} x_{n}\right)\right) \\
= & \|q\|^{2}-2\left\langle q, \beta_{n, 0} J x_{n}+\sum_{i=1}^{\infty} \beta_{n, i} J T_{i}^{n} x_{n}\right\rangle+\left\|\beta_{n, 0} J x_{n}+\sum_{i=1}^{\infty} \beta_{n, i} J T_{i}^{n} x_{n}\right\|^{2} \\
\leq & \|q\|^{2}-2 \beta_{n, 0}\left\langle q, J x_{n}\right\rangle-2 \sum_{i=1}^{\infty} \beta_{n, i}\left\langle q, J T_{i}^{n} x_{n}\right\rangle+\beta_{n, 0}\left\|x_{n}\right\|^{2} \\
& +\sum_{i=1}^{\infty} \beta_{n, i}\left\|T_{i}^{n} x_{n}\right\|^{2}-\beta_{n, 0} \beta_{n, l} g\left(\left\|J x_{n}-J T_{l}^{n} x_{n}\right\|\right) \\
= & \beta_{n, 0} \phi\left(q, x_{n}\right)+\sum_{i=1}^{\infty} \beta_{n, i} \phi\left(q, T_{i}^{n} x_{n}\right)-\beta_{n, 0} \beta_{n, l} g\left(\left\|J x_{n}-J T_{l}^{n} x_{n}\right\|\right) \\
\leq & \beta_{n, 0} \phi\left(q, x_{n}\right)+\sum_{i=1}^{\infty} \beta_{n, i}\left\{\phi\left(q, x_{n}\right)+v_{n} \zeta\left(\phi\left(q, x_{n}\right)\right)+\mu_{n}\right\} \\
& -\beta_{n, 0} \beta_{n, l} g\left(\left\|J x_{n}-J T_{l}^{n} x_{n}\right\|\right) \\
\leq & \phi\left(q, x_{n}\right)+v_{n} \sup _{p \in \Theta} \phi\left(p, x_{n}\right)+\mu_{n}-\beta_{n, 0} \beta_{n, l} g\left(\left\|J x_{n}-J T_{l}^{n} x_{n}\right\|\right) \\
= & \phi\left(q, x_{n}\right)+\xi_{n}-\beta_{n, 0} \beta_{n, l} g\left(\left\|J x_{n}-J T_{l}^{n} x_{n}\right\|\right) .
\end{aligned}
$$

Substituting (3.4) into (3.3), we get

$$
\begin{aligned}
\phi\left(q, u_{n}\right) & \leq \alpha_{n} \phi\left(q, x_{n}\right)+\left(1-\alpha_{n}\right) \phi\left(q, z_{n}\right) \\
& \leq \alpha_{n} \phi\left(q, x_{n}\right)+\left(1-\alpha_{n}\right)\left[\phi\left(q, x_{n}\right)+\xi_{n}-\beta_{n, 0} \beta_{n, l} g\left(\left\|J x_{n}-J T_{l}^{n} x_{n}\right\|\right)\right] \\
& \leq \phi\left(q, x_{n}\right)+\left(1-\alpha_{n}\right) \xi_{n} .
\end{aligned}
$$

This shows that $q \in C_{n+1}$. Further, this implies that $\Theta \subset C_{n+1}$ and hence $\Theta \subset C_{n}$ for all $n \geq 0$. Since $\Theta$ is nonempty, $C_{n}$ is a nonempty closed convex subset of $E$, and hence $\Pi_{C_{n}}$ exists for all $n \geq 0$. This implies that the sequence $\left\{x_{n}\right\}$ is well defined.

Moreover, by the assumption of $\left\{v_{n}\right\},\left\{\mu_{n}\right\}$, and $\Theta$, from (1.4), we have

$$
\xi_{n}=v_{n} \sup _{p \in \Theta} \zeta\left(\phi\left(p, x_{n}\right)\right)+\mu_{n} \longrightarrow 0, \quad n \longrightarrow \infty
$$


Step 3. $\left\{x_{n}\right\}$ is bounded and $\left\{\phi\left(x_{n}, x_{0}\right)\right\}$ is a convergent sequence.

It follows from (3.1) and Lemma 2.4 that

$$
\begin{aligned}
\phi\left(x_{n}, x_{0}\right) & =\phi\left(\Pi_{C_{n}} x_{0}, x_{0}\right) \\
& \leq \phi\left(p, x_{0}\right)-\phi\left(p, x_{n}\right) \\
& \leq \phi\left(p, x_{0}\right), \quad \forall p \in C_{n+1}, \quad \forall n \geq 0 .
\end{aligned}
$$

From definition of $C_{n+1}$ that $x_{n}=\Pi_{C_{n}} x_{0}$ and $x_{n+1}=\Pi_{C_{n+1}} x_{0}$, we have

$$
\phi\left(x_{n}, x_{0}\right) \leq \phi\left(x_{n+1}, x_{0}\right), \quad \forall n \geq 0 .
$$

Therefore, $\left\{\phi\left(x_{n}, x_{0}\right)\right\}$ is nondecreasing and bounded. So, $\left\{\phi\left(x_{n}, x_{0}\right)\right\}$ is a convergent sequence, without loss of generality, we can assume that $\lim _{n \rightarrow \infty} \phi\left(x_{n}, x_{0}\right)=d \geq 0$. In particular, by (1.4), the sequence $\left\{\left(\left\|x_{n}\right\|-\left\|x_{0}\right\|\right)^{2}\right\}$ is bounded. This implies $\left\{x_{n}\right\}$ is also bounded.

Step 4 . We prove that $\left\{x_{n}\right\}$ converges strongly to some point $p \in C$.

Since $\left\{x_{n}\right\}$ is bounded and $E$ is reflexive, there exists a subsequence $\left\{x_{n_{i}}\right\} \subset\left\{x_{n}\right\}$ such that $x_{n_{i}} \rightarrow p$ (some point in $C$ ). Since $C_{n}$ is closed and convex and $C_{n+1} \subset C_{n}$, this implies that $C_{n}$ is weakly closed and $p \in C_{n}$ for each $n \geq 0$. From $x_{n_{i}}=\prod_{C_{n_{i}}} x_{0}$, we have

$$
\phi\left(x_{n_{i}}, x_{0}\right) \leq \phi\left(p, x_{0}\right), \quad \forall n_{i} \geq 0
$$

Since the norm $\|\cdot\|$ is weakly lower semicontinuous, we have

$$
\begin{aligned}
\liminf _{n_{i} \rightarrow \infty} \phi\left(x_{n_{i}}, x_{0}\right) & =\liminf _{n_{i} \rightarrow \infty}\left\{\left\|x_{n_{i}}\right\|^{2}-2\left\langle x_{n_{i}}, J x_{0}\right\rangle+\left\|x_{0}\right\|^{2}\right\} \\
& \geq\|p\|^{2}-2\left\langle p, J x_{0}\right\rangle+\left\|x_{0}\right\|^{2} \\
& =\phi\left(p, x_{0}\right),
\end{aligned}
$$

and so

$$
\phi\left(p, x_{0}\right) \leq \liminf _{n_{i} \rightarrow \infty} \phi\left(x_{n_{i}}, x_{0}\right) \leq \limsup _{n_{i} \rightarrow \infty} \phi\left(x_{n_{i}}, x_{0}\right) \leq \phi\left(p, x_{0}\right) .
$$

This implies that $\lim _{n_{i} \rightarrow \infty} \phi\left(x_{n_{i}}, x_{0}\right) \rightarrow \phi\left(p, x_{0}\right)$, and so $\left\|x_{n}\right\| \rightarrow\|p\|$. Since $x_{n_{i}} \rightarrow p$, by virtue of the Kadec-Klee property of $E$, we obtain that

$$
\lim _{n_{i} \rightarrow \infty} x_{n_{i}}=p
$$


Since $\left\{\phi\left(x_{n}, x_{0}\right)\right\}$ is convergent, this together with $\lim _{n_{i} \rightarrow \infty} \phi\left(x_{n_{i}}, x_{0}\right)=\phi\left(p, x_{0}\right)$, we have $\lim _{n \rightarrow \infty} \phi\left(x_{n}, x_{0}\right)=\phi\left(p, x_{0}\right)$. If there exists some subsequence $\left\{x_{n_{j}}\right\} \subset\left\{x_{n}\right\}$ such that $x_{n_{j}} \rightarrow q$, then from Lemma 2.4, we have that

$$
\begin{aligned}
\phi(p, q) & =\lim _{n_{i}, n_{j} \rightarrow \infty} \phi\left(x_{n_{i}}, x_{n_{j}}\right) \\
& =\lim _{n_{i}, n_{j} \rightarrow \infty} \phi\left(x_{n_{i}}, \Pi_{C_{n_{j}}} x_{0}\right) \\
& \leq \lim _{n_{i}, n_{j} \rightarrow \infty}\left(\phi\left(x_{n_{i}}, x_{0}\right)-\phi\left(\Pi_{C_{n_{j}}} x_{0}, x_{0}\right)\right) \\
& =\lim _{n_{i}, n_{j} \rightarrow \infty}\left(\phi\left(x_{n_{i}}, x_{0}\right)-\phi\left(x_{n_{j}}, x_{0}\right)\right) \\
& =\phi\left(p, x_{0}\right)-\phi\left(p, x_{0}\right) \\
& =0 .
\end{aligned}
$$

This implies that $p=q$ and

$$
\lim _{n \rightarrow \infty} x_{n}=p
$$

Step 5. We prove that $\lim _{n \rightarrow \infty}\left\|J x_{n}-J u_{n}\right\|=0$.

By definition of $\Pi_{C_{n}} x_{0}$, we have

$$
\begin{aligned}
\phi\left(x_{n+1}, x_{n}\right) & =\phi\left(x_{n+1}, \Pi_{C_{n}} x_{0}\right) \\
& \leq \phi\left(x_{n+1}, x_{0}\right)-\phi\left(\Pi_{C_{n}} x_{0}, x_{0}\right) \\
& =\phi\left(x_{n+1}, x_{0}\right)-\phi\left(x_{n}, x_{0}\right) .
\end{aligned}
$$

Since $\lim _{n \rightarrow \infty} \phi\left(x_{n}, x_{0}\right)$ exists, we have

$$
\lim _{n \rightarrow \infty} \phi\left(x_{n+1}, x_{n}\right)=0
$$

Since $x_{n+1}=\prod_{C_{n+1}} x_{0} \in C_{n+1} \subset C_{n}$ and the definition of $C_{n+1}$, we get

$$
\phi\left(x_{n+1}, u_{n}\right) \leq \phi\left(x_{n+1}, x_{n}\right)+\xi_{n} .
$$

It follows from (3.6) and (3.16) that

$$
\lim _{n \rightarrow \infty} \phi\left(x_{n+1}, u_{n}\right)=0 .
$$

From (1.4), we have

$$
\lim _{n \rightarrow \infty}\left\|u_{n}\right\|=p
$$


So,

$$
\lim _{n \rightarrow \infty}\left\|J u_{n}\right\|=J p .
$$

This implies that $\left\{J u_{n}\right\}$ is bounded in $E^{*}$. Note that $E$ is reflexive and $E^{*}$ is also reflexive, we can assume that $J u_{n} \rightarrow x^{*} \in E^{*}$. In view of the reflexive of $E$, we know that $J(E)=E^{*}$. Hence, there exist $x \in C$ such that $J x=x^{*}$. It follows that

$$
\begin{aligned}
\phi\left(x_{n+1}, u_{n}\right) & =\left\|x_{n+1}\right\|^{2}-2\left\langle x_{n+1}, J u_{n}\right\rangle+\left\|u_{n}\right\|^{2} \\
& =\left\|x_{n+1}\right\|^{2}-2\left\langle x_{n+1}, J u_{n}\right\rangle+\left\|J u_{n}\right\|^{2} .
\end{aligned}
$$

Taking $\lim \inf _{n \rightarrow \infty}$ on the both sides of equality above and by the weak lower semicontinuity of norm $\|\cdot\|$, we have

$$
\begin{aligned}
0 & \geq\|p\|^{2}-2\left\langle p, x^{*}\right\rangle+\left\|x^{*}\right\|^{2} \\
& =\|p\|^{2}-2\langle p, J x\rangle+\|J x\|^{2} \\
& =\|p\|^{2}-2\langle p, J x\rangle+\|x\|^{2} \\
& =\phi(p, x) .
\end{aligned}
$$

That is, $p=x$, which implies that $x^{*}=J p$. It follows that $J u_{n} \rightarrow J p \in E^{*}$. From (1.4) and the Kadec-Klee property of $E$, we have

$$
\lim _{n \rightarrow \infty} u_{n}=p
$$

Since $\left\|x_{n}-u_{n}\right\| \leq\left\|x_{n}-p\right\|+\left\|p-u_{n}\right\|$, so,

$$
\liminf _{n \rightarrow \infty}\left\|x_{n}-u_{n}\right\|=0
$$

Since $J$ is uniformly norm-to-norm continuous on bounded subsets of $E$, we obtain

$$
\liminf _{n \rightarrow \infty}\left\|J x_{n}-J u_{n}\right\|=0,
$$

Step 6. We show that $p \in \Theta:=\bigcap_{i=1}^{\infty} F\left(T_{i}\right) \bigcap \operatorname{GMEP}(f, B, \varphi)$.

First, we show that $p \in \bigcap_{i=1}^{\infty} F\left(T_{i}\right)$.

Since $x_{n+1} \in C_{n+1}$, it follows from (3.1) and (3.14) that

$$
\phi\left(x_{n+1}, u_{n}\right) \leq \phi\left(x_{n+1}, x_{n}\right)+\xi_{n} \longrightarrow 0 \quad(\text { as } n \longrightarrow \infty) .
$$

Since $x_{n} \rightarrow p$, by Lemma 2.3,

$$
\lim _{n \rightarrow \infty} u_{n}=p
$$


By (3.3) and (3.4), for any $q \in \Theta$, we have

$$
\phi\left(q, u_{n}\right) \leq \phi\left(q, x_{n}\right)+\xi_{n}-\left(1-\alpha_{n}\right) \beta_{n, 0} \beta_{n, l} g\left(\left\|J x_{n}-J T_{l}^{n} x_{n}\right\|\right) .
$$

So,

$$
\left(1-\alpha_{n}\right) \beta_{n, 0} \beta_{n, l} g\left\|J x_{n}-J T_{l}^{n} x_{n}\right\| \leq \phi\left(q, x_{n}\right)+\xi_{n}-\phi\left(q, u_{n}\right) \longrightarrow 0 \quad(\text { as } n \longrightarrow \infty) .
$$

Therefore,

$$
\lim _{n \rightarrow \infty}\left(1-\alpha_{n}\right) \beta_{n, 0} \beta_{n, l} g\left\|J x_{n}-J T_{l}^{n} x_{n}\right\|=0
$$

In view of the property of $g$, we have

$$
\left\|J x_{n}-J T_{l}^{n} x_{n}\right\| \longrightarrow 0 \quad(\text { as } n \longrightarrow \infty)
$$

Since $J x_{n} \rightarrow J p$, this implies that $\lim _{n \rightarrow \infty} J T_{l}^{n} x_{n}=J p$. From Remark 1.1(ii), it yields

$$
T_{l}^{n} x_{n} \rightarrow p \quad(\text { as } n \longrightarrow \infty)
$$

Again since

$$
\left\|T_{l}^{n} x_{n}\right\|-\|p\|=\left\|J\left(T_{l}^{n} x_{n}\right)\right\|-\|J p\| \leq\left\|J\left(T_{l}^{n} x_{n}\right)-J p\right\| \longrightarrow 0 \quad(\text { as } n \longrightarrow \infty),
$$

this together with (3.32) and the Kadec-Klee-property of $E$ shows that

$$
\lim _{n \rightarrow \infty} T_{l}^{n} x_{n}=p
$$

By the assumption that $T_{l}$ is uniformly $L_{l}$-Lipschitz continuous, we have

$$
\begin{aligned}
\left\|T_{l}^{n+1} x_{n}-T_{l}^{n} x_{n}\right\| \leq & \left\|T_{l}^{n+1} x_{n}-T_{l}^{n+1} x_{n+1}\right\|+\left\|T_{l}^{n+1} x_{n+1}-x_{n+1}\right\| \\
& +\left\|x_{n+1}-x_{n}\right\|+\left\|x_{n}-T_{l}^{n} x_{n}\right\| \\
\leq & \left(L_{l}+1\right)\left\|x_{n+1}-x_{n}\right\|+\left\|T_{l}^{n+1} x_{n+1}-x_{n+1}\right\|+\left\|x_{n}-T_{l}^{n} x_{n}\right\| .
\end{aligned}
$$

This together with (3.34) and $x_{n} \rightarrow p$ shows that $\lim _{n \rightarrow \infty}\left\|T_{l}^{n+1} x_{n}-T_{l}^{n} x_{n}\right\|=0$ and $\lim _{n \rightarrow \infty} T_{l}^{n+1}$ $x_{n}=p$, that is, $\lim _{n \rightarrow \infty} T_{l} T_{l}^{n} x_{n}=p$. In view of the closeness of $T_{l}$, it follows that $T_{l} p=p$, that is, $p \in F\left(T_{l}\right)$. By the arbitrariness of $l \geq 1$, we have $p \in \cap_{i=1}^{\infty} F\left(T_{i}\right)$. 
Now, we show that $p \in \operatorname{GMEP}(f, B, \varphi)$.

It follows from (3.2), (3.3), (3.6), Lemma 2.4, and $u_{n}=K_{r_{n}} y_{n}$ that

$$
\begin{aligned}
\phi\left(u_{n}, y_{n}\right) & =\phi\left(K_{r_{n}} y_{n}, y_{n}\right) \\
& \leq \phi\left(p, y_{n}\right)-\phi\left(p, K_{r_{n}} y_{n}\right) \\
& \leq \phi\left(p, x_{n}\right)-\phi\left(p, K_{r_{n}} y_{n}\right)+\xi_{n} \\
& =\phi\left(p, x_{n}\right)-\phi\left(p, u_{n}\right)+\xi_{n} \longrightarrow 0, \quad(\text { as } n \longrightarrow \infty) .
\end{aligned}
$$

By (1.4), we have

$$
\left\|u_{n}\right\| \longrightarrow\left\|y_{n}\right\|, \quad(\text { as } n \longrightarrow \infty)
$$

Since $u_{n} \rightarrow p$ as $n \rightarrow \infty$, so

$$
\left\|y_{n}\right\| \longrightarrow\|p\|, \quad(\text { as } n \longrightarrow \infty)
$$

Therefore,

$$
\left\|J u_{n}\right\| \longrightarrow\|J p\|, \quad(\text { as } n \longrightarrow \infty)
$$

Since $E^{*}$ is reflexive, we may assume that $J y_{n} \rightarrow z^{*} \in E^{*}$. In view of the reflexive of $E$, we have $J(E)=E^{*}$. Hence, there exist $z \in E$ such that $J z=z^{*}$. It follows that

$$
\begin{aligned}
\phi\left(u_{n}, y_{n}\right) & =\left\|u_{n}\right\|^{2}-2\left\langle u_{n}, J y_{n}\right\rangle+\left\|y_{n}\right\|^{2} \\
& =\left\|u_{n}\right\|^{2}-2\left\langle u_{n}, J y_{n}\right\rangle+\left\|J y_{n}\right\|^{2}
\end{aligned}
$$

Taking $\lim \inf _{n \rightarrow \infty}$ on the both sides of equality above yields that

$$
\begin{aligned}
0 & \geq\|p\|^{2}-2\left\langle p, z^{*}\right\rangle+\left\|z^{*}\right\|^{2} \\
& =\|p\|^{2}-2\langle p, J z\rangle+\|J z\|^{2} \\
& =\|p\|^{2}-2\langle p, J z\rangle+\|z\|^{2} \\
& =\phi(p, x) .
\end{aligned}
$$

That is, $p=z$, which implies that $z^{*}=J p$. It follows that $J y_{n} \rightarrow J p \in E^{*}$. Since $J^{-1}$ is normweak ${ }^{*}$-continuous, it follows that $y_{n} \rightarrow p$. From (3.38) and $E$ with the Kadec-Klee property, we obtain

$$
y_{n} \longrightarrow p \quad(\text { as } n \longrightarrow \infty)
$$


It follows from (3.23) and (3.42) that

$$
\lim _{n \rightarrow \infty}\left\|u_{n}-y_{n}\right\|=0
$$

Since $J$ is uniformly norm-to-norm continuous, we have

$$
\lim _{n \rightarrow \infty}\left\|J u_{n}-J y_{n}\right\|=0
$$

By Lemma 2.2, we have

$$
f\left(u_{n}, y\right)+\varphi(y)-\varphi\left(u_{n}\right)+\left\langle B y_{n}, y-u_{n}\right\rangle+\frac{1}{r_{n}}\left\langle y-u_{n}, J u_{n}-J y_{n}\right\rangle \geq 0, \quad \forall y \in C
$$

From (A2), we have

$$
\varphi(y)-\varphi\left(u_{n}\right)+\left\langle B y_{n}, y-u_{n}\right\rangle+\frac{1}{r_{n}}\left\langle y-u_{n}, J u_{n}-J y_{n}\right\rangle \geq-f\left(u_{n}, y\right) \geq f\left(y, u_{n}\right), \quad \forall y \in C
$$

Put $z_{t}=t y+(1-t) p$ for all $t \in(0,1]$ and $y \in C$. Consequently, we get $z_{t} \in C$. It follows from (3.46) that

$$
\begin{aligned}
\left\langle B z_{t}, z_{t}-u_{n}\right\rangle \geq & \left\langle B z_{t}, z_{t}-u_{n}\right\rangle-\varphi\left(z_{t}\right)+\varphi\left(u_{n}\right) \\
& -\left\langle B y_{n}, z_{t}-u_{n}\right\rangle+f\left(z_{t}, u_{n}\right) \\
& -\left\langle z_{t}-u_{n}, \frac{J u_{n}-J y_{n}}{r_{n}}\right\rangle \\
= & \left\langle B z_{t}-B u_{n}, z_{t}-u_{n}\right\rangle-\varphi\left(z_{t}\right)+\varphi\left(u_{n}\right) \\
& +\left\langle B u_{n}-B y_{n}, z_{t}-u_{n}\right\rangle+f\left(z_{t}, u_{n}\right) \\
& -\left\langle z_{t}-u_{n}, \frac{J u_{n}-J y_{n}}{r_{n}}\right\rangle .
\end{aligned}
$$

Since $B$ is continuous, and from (3.43), and $u_{n} \rightarrow p, y_{n} \rightarrow p$, as $n \rightarrow \infty$, therefore $\| B u_{n}-$ $B y_{n} \| \rightarrow 0$. Since $B$ is monotone, we know that $\left\langle B z_{t}-B u_{n}, z_{t}-u_{n}\right\rangle \geq 0$. Further, $\lim _{n \rightarrow \infty} \| J u_{n}-$ $J y_{n} \| / r_{n}=0$. So, it follows from (A4), and the weak lower semicontinuity of $\varphi$ and (3.43) that

$$
\begin{aligned}
f\left(z_{t}, p\right)-\varphi\left(z_{t}\right)+\varphi(p) & \leq \lim _{n \rightarrow \infty}\left\langle B z_{t}, z_{t}-u_{n}\right\rangle \\
& =\left\langle B z_{t}, z_{t}-p\right\rangle
\end{aligned}
$$


From (A1) and (3.48), we have

$$
\begin{aligned}
0 & =f\left(z_{t}, z_{t}\right)-\varphi\left(z_{t}\right)+\varphi\left(z_{t}\right) \\
& \leq t f\left(z_{t}, y\right)+(1-t) f\left(z_{t}, p\right)+t \varphi(y)+(1-t) \varphi(p)-\varphi\left(z_{t}\right) \\
& =t\left[f\left(z_{t}, y\right)+\varphi(y)-\varphi\left(z_{t}\right)\right]+(1-t)\left[f\left(z_{t}, p\right)+\varphi(p)-\varphi\left(z_{t}\right)\right] \\
& \leq t\left[f\left(z_{t}, y\right)+\varphi(y)-\varphi\left(z_{t}\right)\right]+(1-t)\left\langle B z_{t}, z_{t}-p\right\rangle \\
& \leq t\left[f\left(z_{t}, y\right)+\varphi(y)-\varphi\left(z_{t}\right)\right]+(1-t) t\left\langle B z_{t}, y-p\right\rangle,
\end{aligned}
$$

and hence

$$
f\left(z_{t}, y\right)+\varphi(y)-\varphi\left(z_{t}\right)+(1-t)\left\langle B z_{t}, y-p\right\rangle \geq 0
$$

Letting $t \rightarrow 0$, we have

$$
f(p, y)+\varphi(y)-\varphi(p)+\langle B p, y-p\rangle \geq 0
$$

This implies that $p \in \operatorname{GMEP}(f, B, \varphi)$. Hence, $p \in \cap_{i=1}^{\infty} F\left(T_{i}\right) \cap \operatorname{GMEP}(f, B, \varphi)$.

Step 7. We prove that $x_{n} \rightarrow p=\Pi_{\Theta} x_{0}$.

Let $q=\Pi_{\Theta} x_{0}$. From $x_{n}=\Pi_{C_{n}} x_{0}$ and $q \in \Theta \subset C_{n}$, we have

$$
\phi\left(x_{n}, x_{0}\right) \leq \phi\left(q, x_{0}\right), \quad \forall n \geq 0 .
$$

This implies that

$$
\phi\left(p, x_{0}\right)=\lim _{n \rightarrow \infty} \phi\left(x_{n}, x_{0}\right) \leq \phi\left(q, x_{0}\right) .
$$

By definition of $p=\Pi_{\Theta} x_{0}$, we have $p=q$. Therefore, $x_{n} \rightarrow p=\Pi_{\Theta} x_{0}$. This completes the proof.

Taking $\varphi=0, T_{i}=T$ for each $i \in N$ in Theorem 3.1, we have the following result.

Corollary 3.2. Let $C$ be a nonempty, closed, and convex subset of an uniformly smooth and strictly convex Banach Banach space $E$ with Kadec-Klee property. Let $B: C \rightarrow E^{*}$ be a continuous and monotone mapping. Let $f$ be a bifunction from $C \times C$ to $R$ satisfying (A1)-(A4). Let $T: C \rightarrow C$ be a closed uniformly L-Lipschitz continuous and uniformly total quasi- $\phi$-asymptotically nonexpansive mappings with nonnegative real sequences $\left\{v_{n}\right\},\left\{\mu_{n}\right\}$ and a strictly increasing continuous function 
$\zeta: R^{+} \rightarrow R^{+}$such that $\mu_{1}=0, v_{n} \rightarrow 0, \mu_{n} \rightarrow 0($ as $n \rightarrow \infty)$, and $\zeta(0)=0$. Let $\left\{x_{n}\right\}$ be the sequence generated by

$$
\begin{gathered}
x_{0} \in C \text { chosen arbitrary, } C_{0}=C, \\
y_{n}=J^{-1}\left(\alpha_{n} J x_{n}+\left(1-\alpha_{n}\right) J z_{n}\right), \\
z_{n}=J^{-1}\left(\beta_{n} J x_{n}+\left(1-\beta_{n}\right) J T^{n} x_{n}\right), \\
u_{n} \in C \text { such that } f\left(u_{n}, y\right)+\left\langle B y_{n}, y-u_{n}\right\rangle+\frac{1}{r_{n}}\left\langle y-u_{n} J u_{n}-J y_{n}\right\rangle \geq 0, \quad \forall y \in C, \\
C_{n+1}=\left\{v \in C_{n}: \phi\left(v, u_{n}\right) \leq \phi\left(v, x_{n}\right)+\xi_{n}\right\}, \\
x_{n+1}=\Pi_{C_{n+1}} x_{0}, \quad n \geq 0,
\end{gathered}
$$

where $\xi_{n}=v_{n} \sup _{q \in \Theta} \zeta\left(\phi\left(q, x_{n}\right)\right)+\mu_{n}, \Pi_{C_{n+1}}$ is the generalized projection of $E$ onto $C_{n+1},\left\{\beta_{n}\right\}$ and $\left\{\alpha_{n}\right\}$ are sequences in $[0,1], \liminf _{n \rightarrow \infty} \beta_{n}\left(1-\beta_{n}\right)>0,\left\{r_{n}\right\} \subset[a, \infty)$ for some a $>0$. If $\Theta:=$ $\cap_{i=1}^{\infty} F\left(T_{i}\right) \cap \operatorname{GEP}(f, B)$ is a nonempty and bounded subset in $C$, then the sequence $\left\{x_{n}\right\}$ converges strongly to $p \in \Theta$, where $p=\Pi_{\Theta} x_{0}$. corollary.

In Theorem 3.1, as $\varphi=0, B=0, T_{i}=T$ for each $i \in N$, we can obtain the following

Corollary 3.3. Let $C$ be a nonempty, closed and convex subset of an uniformly smooth and strictly convex Banach Banach space $E$ with Kadec-Klee property. Let $f$ be a bifunction from $C \times C$ to $R$ satisfying (A1)-(A4), and $T: C \rightarrow C$ be a closed uniformly L-Lipschitz continuous and uniformly total quasi- $\phi$-asymptotically nonexpansive mappings with nonnegative real sequences $\left\{v_{n}\right\},\left\{\mu_{n}\right\}$ and a strictly increasing continuous function $\zeta: R^{+} \rightarrow R^{+}$such that $\mu_{1}=0, v_{n} \rightarrow 0, \mu_{n} \rightarrow 0$ (as $n \rightarrow \infty)$ and $\zeta(0)=0$. Let $\left\{x_{n}\right\}$ be the sequence generated by

$$
\begin{gathered}
x_{0} \in C \text { chosen arbitrary, } C_{0}=C, \\
y_{n}=J^{-1}\left(\alpha_{n} J x_{n}+\left(1-\alpha_{n}\right) J z_{n}\right), \\
z_{n}=J^{-1}\left(\beta_{n} J x_{n}+\left(1-\beta_{n}\right) J T^{n} x_{n}\right), \\
u_{n} \in C \text { such that } f\left(u_{n}, y\right)+\frac{1}{r_{n}}\left\langle y-u_{n} J u_{n}-J y_{n}\right\rangle \geq 0, \quad \forall y \in C, \\
C_{n+1}=\left\{v \in C_{n}: \phi\left(v, u_{n}\right) \leq \phi\left(v, x_{n}\right)+\xi_{n}\right\}, \\
x_{n+1}=\prod_{C_{n+1}} x_{0}, \quad n \geq 0,
\end{gathered}
$$

where $\xi_{n}=v_{n} \sup _{q \in \Theta} \xi\left(\phi\left(q, x_{n}\right)\right)+\mu_{n}, \Pi_{C_{n+1}}$ is the generalized projection of $E$ onto $C_{n+1},\left\{\beta_{n}\right\}$ and $\left\{\alpha_{n}\right\}$ are sequences in $[0,1], \liminf _{n \rightarrow \infty} \beta_{n}\left(1-\beta_{n}\right)>0,\left\{r_{n}\right\} \subset[a, \infty)$ for some $a>0$. If $\Theta:=$ $\cap_{i=1}^{\infty} F\left(T_{i}\right) \cap \mathrm{EP}(f)$ is a nonempty and bounded subset in $C$, then the sequence $\left\{x_{n}\right\}$ converges strongly to $p \in \Theta$, where $p=\Pi_{\Theta} x_{0}$. 
Definition 3.4. A countable family of mapping $\left\{T_{n}\right\}: C \rightarrow C$ is said to be uniformly quasi$\phi$-asymptotically nonexpansive, if $\cap_{i=1}^{\infty} F\left(T_{i}\right) \neq \emptyset$ and there exist real sequences $\left\{k_{n}\right\} \subset[1, \infty)$, $k_{n} \rightarrow 1$ such that for each $\mathrm{i} \geq 1$,

$$
\phi\left(p, T_{i}^{n} x\right) \leq k_{n} \phi(p, x), \quad \forall x \in C, \quad p \in \bigcap_{i=1}^{\infty} F\left(T_{i}\right) .
$$

The following Corollary can be directly obtained from Theorem 3.1.

Corollary 3.5. Let $C$ be a nonempty, closed and convex subset of an uniformly smooth and strictly convex Banach Banach space $E$ with Kadec-Klee property. Let $B: C \rightarrow E^{*}$ be a continuous and monotone mapping and let $\varphi: C \rightarrow R$ be a lower semicontinuous and convex function. Let $f$ be a bifunction from $C \times C$ to $R$ satisfying $(A 1)-(A 4)$. Let $\left\{T_{i}\right\}_{i=1}^{\infty}: C \rightarrow C$ be an infinite family of closed and uniformly $L_{i}$-Lipschitz continuous and uniformly quasi- $\phi$-asymptotically nonexpansive mappings with a sequence $\left\{k_{n}\right\} \subset[1, \infty), k_{n} \rightarrow 1$ such that $\Theta:=\cap_{i=1}^{\infty} F\left(T_{i}\right) \cap \operatorname{GMEP}(f, B, \varphi)$ is a nonempty and bounded subset in $C$. Let $\left\{x_{n}\right\}$ be the sequence generated by

$$
\begin{gathered}
x_{0} \in C \text { chosen arbitrary, } C_{0}=C, \\
y_{n}=J^{-1}\left(\alpha_{n} J x_{n}+\left(1-\alpha_{n}\right) J z_{n}\right), \\
z_{n}=J^{-1}\left(\beta_{n, 0} J x_{n}+\sum_{i=1}^{\infty} \beta_{n, i} J T_{i}^{n} x_{n}\right), \\
u_{n} \in C \text { such that } u_{n}=K_{r_{n}} y_{n}, \\
C_{n+1}=\left\{z \in C_{n}: \phi\left(z, u_{n}\right) \leq \phi\left(z, x_{n}\right)+\xi_{n}\right\}, \\
x_{n+1}=\Pi_{C_{n+1}} x_{0}, \quad n \geq 0,
\end{gathered}
$$

where $\xi_{n}=\sup _{p \in F}\left(k_{n}-1\right) \phi\left(p, x_{n}\right), \Pi_{C_{n+1}}$ is the generalized projection of $E$ onto $C_{n+1},\left\{r_{n}\right\} \subset[a, \infty)$ for some $a>0,\left\{\beta_{n, 0}, \beta_{n, i}\right\}$ and $\left\{\alpha_{n}\right\}$ are sequences in $[0,1]$. If $\sum_{i=1}^{\infty} \beta_{n, i}=1$ for all $n \geq 0$, and $\lim \inf _{n \rightarrow \infty} \beta_{n, 0} \beta_{n, i}>0$ for all $i \geq 1$, then the sequence $\left\{x_{n}\right\}$ converges strongly to $p \in \Theta$, where $p=\Pi_{\Theta} x_{0}$.

Remark 3.6. Theorem 3.1 improves and extend the corresponding results in [13, 24-29] in the following aspects:

(1) for the mappings, extend the mappings from relatively nonexpansive mappings, quasi- $\phi$-nonexpansive mappings, and quasi- $\phi$-asymptotically nonexpansive mappings to a countable family of total quasi- $\phi$-asymptotically nonexpansive mappings;

(2) for the framework of spaces, extend the space from an uniformly smooth and uniformly convex Banach space to an uniformly smooth and strictly convex Banach space with the Kadec-Klee property.

\section{Acknowledgment}

This work was supported by the Natural Science Foundation of Yunnan Province (no. 2011FB074). 


\section{References}

[1] I. Cioranescu, Geometry of Banach Spaces, Duality Mappings and Nonlinear Problems, vol. 62 of Mathematics and its Applications, Kluwer Academic, Dordrecht, The Netherlands, 1990.

[2] W. Takahashi, Nonlinear Functional Analysis, Yokohama, Yokohama, Japan, 2000, Fixed point theory and its applications.

[3] Y. I. Alber, "Metric and generalized projection operators in Banach spaces: properties and applications," in Theory and Applications of Nonlinear Operators of Accretive and Monotone Type, A. G. Kartsatos, Ed., vol. 178, pp. 15-50, Marcel Dekker, New York, NY, USA, 1996.

[4] Ya. I. Alber and S. Reich, "An iterative method for solving a class of nonlinear operator equations in Banach spaces," Panamerican Mathematical Journal, vol. 4, no. 2, pp. 39-54, 1994.

[5] S. Kamimura and W. Takahashi, "Strong convergence of a proximal-type algorithm in a Banach space," SIAM Journal on Optimization, vol. 13, no. 3, pp. 938-945, 2002.

[6] S. Reich, "A weak convergence theorem for the alternating method with Bregman distances," in Theory and Applications of Nonlinear Operators of Accretive and Monotone Type, A. G. Kartsatos, Ed., vol. 178, pp. 313-318, Marcel Dekker, New York, NY, USA, 1996.

[7] W. Nilsrakoo and S. Saejung, "Strong convergence to common fixed points of countable relatively quasi-nonexpansive mappings," Fixed Point Theory and Applications, vol. 2008, Article ID 312454, 19 pages, 2008.

[8] Y. Su, D. Wang, and M. Shang, "Strong convergence of monotone hybrid algorithm for hemi-relatively nonexpansive mappings," Fixed Point Theory and Applications, vol. 2008, Article ID 284613, 8 pages, 2008.

[9] H. Zegeye and N. Shahzad, "Strong convergence theorems for monotone mappings and relatively weak nonexpansive mappings," Nonlinear Analysis, vol. 70, no. 7, pp. 2707-2716, 2009.

[10] D. Butnariu, S. Reich, and A. J. Zaslavski, "Asymptotic behavior of relatively nonexpansive operators in Banach spaces," Journal of Applied Analysis, vol. 7, no. 2, pp. 151-174, 2001.

[11] D. Butnariu, S. Reich, and A. J. Zaslavski, "Weak convergence of orbits of nonlinear operators in reflexive Banach spaces," Numerical Functional Analysis and Optimization, vol. 24, no. 5-6, pp. 489-508, 2003.

[12] Y. Censor and S. Reich, "Iterations of paracontractions and firmly nonexpansive operators with applications to feasibility and optimization," Optimization, vol. 37, no. 4, pp. 323-339, 1996.

[13] S.-y. Matsushita and W. Takahashi, "A strong convergence theorem for relatively nonexpansive mappings in a Banach space," Journal of Approximation Theory, vol. 134, no. 2, pp. 257-266, 2005.

[14] S. Saewan, P. Kumam, and K. Wattanawitoon, "Convergence theorem based on a new hybrid projection method for finding a common solution of generalized equilibrium and variational inequality problems in Banach spaces," Abstract and Applied Analysis, vol. 2010, Article ID 734126, 25 pages, 2010.

[15] J. W. Peng and J. C. Yao, "Two extragradient methods for generalized mixed equilibrium problems, nonexpansive mappings and monotone mappings," Computers $\mathcal{E}$ Mathematics with Applications, vol. 58, no. 7, pp. 1287-1301, 2009.

[16] E. Blum and W. Oettli, "From optimization and variational inequalities to equilibrium problems," The Mathematics Student, vol. 63, no. 1-4, pp. 123-145, 1994.

[17] M. A. Noor and W. Oettli, "On general nonlinear complementarity problems and quasi-equilibria," Le Matematiche, vol. 49, no. 2, pp. 313-331, 1994.

[18] C. Jaiboon and P. Kumam, "A hybrid extragradient viscosity approximation method for solving equilibrium problems and fixed point problems of infinitely many nonexpansive mappings," Fixed Point Theory and Applications, vol. 2009, Article ID 374815, 32 pages, 2009.

[19] Q. Y. Liu, W. Y. Zeng, and N. J. Huang, "An iterative method for generalized equilibrium problems, fixed point problems and variational inequality problems," Fixed Point Theory and Applications, vol. 2009, Article ID 531308, 20 pages, 2009.

[20] A. Moudafi and M. Thera, "Proximal and dynamical approaches to equilibrium problems," in IllPosed Variational Problems and Regularization Techniques (Trier, 1998), vol. 477 of Lecture Notes in Economics and Mathmtical Systems, pp. 187-201, Springer, Berlin, Germany, 1999.

[21] J. W. Peng and J. . Yao, "A viscosity approximation scheme for system of equilibrium problems, nonexpansive mappings and monotone mappings," Nonlinear Analysis, vol. 71, no. 12, pp. 6001-6010, 2009. 
[22] S. S. Chang, C. K. Chan, H. W. J. Lee, and L. Yang, "A system of mixed equilibrium problems, fixed point problems of strictly pseudo-contractive mappings and nonexpansive semi-groups," Applied Mathematics and Computation, vol. 216, no. 1, pp. 51-60, 2010.

[23] P. Kumam and C. Jaiboon, "A new hybrid iterative method for mixed equilibrium problems and variational inequality problem for relaxed cocoercive mappings with application to optimization problems," Nonlinear Analysis. Hybrid Systems, vol. 3, no. 4, pp. 510-530, 2009.

[24] X. Qin, S. Y. Cho, and S. M. Kang, "Strong convergence of shrinking projection methods for quasi- $\phi-$ nonexpansive mappings and equilibrium problems," Journal of Computational and Applied Mathematics, vol. 234, no. 3, pp. 750-760, 2010.

[25] S. Saewan and P. Kumam, "A modified hybrid projection method for solving generalized mixed equilibrium problems and fixed point problems in Banach spaces," Computers $\mathcal{E}$ Mathematics with Applications, vol. 62, no. 4, pp. 1723-1735, 2011.

[26] S. S. Chang, H. W. J. Lee, C. K. Chan, and L. Yang, "Approximation theorems for total quasi- $\phi$-asymptotically nonexpansive mappings with applications," Applied Mathematics and Computation, vol. 218, no. 6, pp. 2921-2931, 2011.

[27] S. Saewan and P. Kumam, “Modified hybrid block iterative algorithm for convex feasibility problems and generalized equilibrium problems for uniformly quasi- $\phi$-asymptotically nonexpansive mappings," Abstract and Applied Analysis, vol. 2010, Article ID 357120, 22 pages, 2010.

[28] S. S. Chang, C. K. Chan, and H. W. J. Lee, "Modified block iterative algorithm for quasi- $\phi$-asymptotically nonexpansive mappings and equilibrium problem in Banach spaces," Applied Mathematics and Computation, vol. 217, no. 18, pp. 7520-7530, 2011.

[29] S. Plubtieng and K. Ungchittrakool, "Strong convergence theorems for a common fixed point of two relatively nonexpansive mappings in a Banach space," Journal of Approximation Theory, vol. 149, no. 2, pp. 103-115, 2007.

[30] S. S. Zhang, "Generalized mixed equilibrium problem in Banach spaces," Applied Mathematics and Mechanics (English Edition), vol. 30, no. 9, pp. 1105-1112, 2009.

[31] S. S. Chang, J. K. Kim, and X. R. Wang, "Modified block iterative algorithm for solving convex feasibility problems in Banach spaces," Journal of Inequalities and Applications, vol. 2010, Article ID 869684, 14 pages, 2010. 


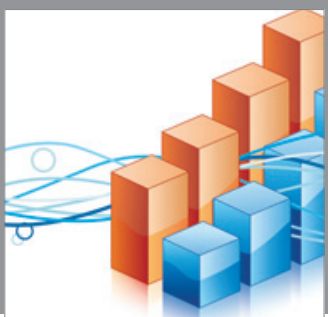

Advances in

Operations Research

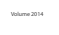

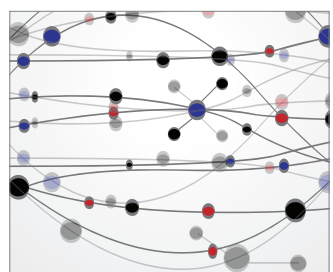

\section{The Scientific} World Journal
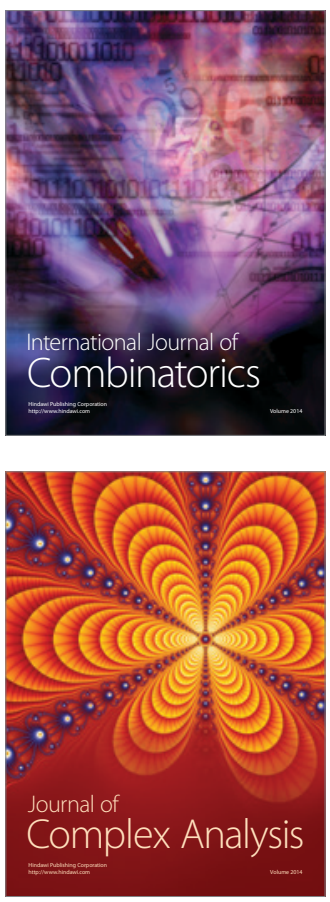

International Journal of

Mathematics and

Mathematical

Sciences
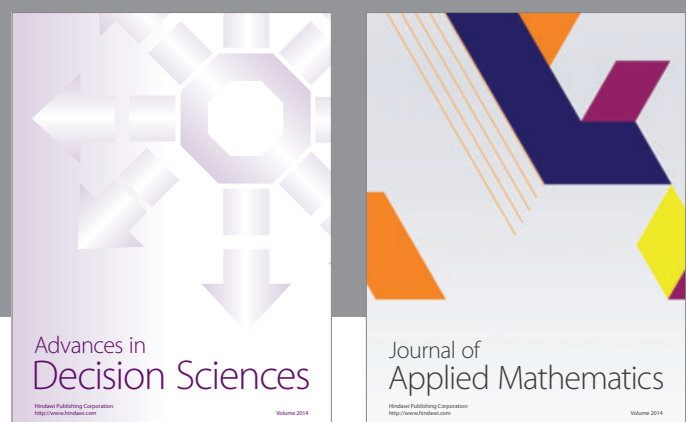

Journal of

Applied Mathematics
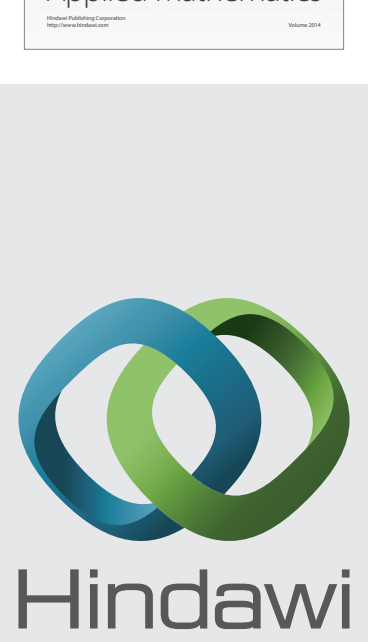

Submit your manuscripts at http://www.hindawi.com
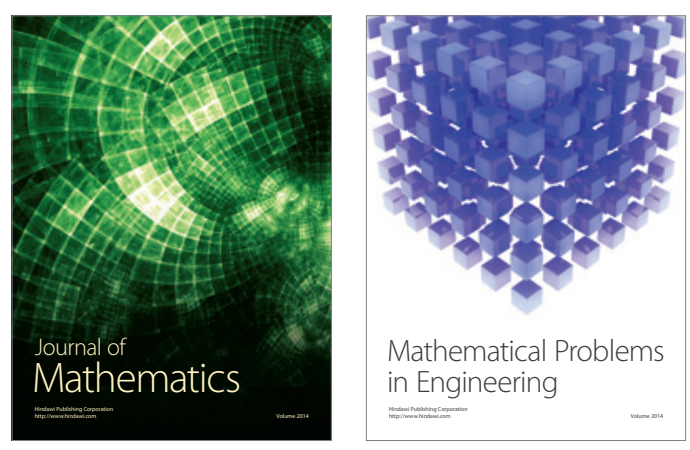

Mathematical Problems in Engineering
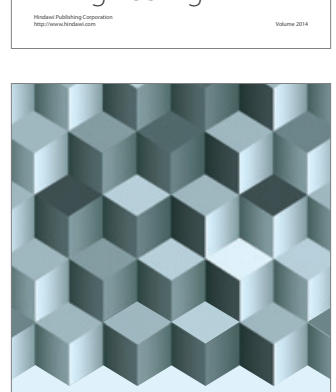

Journal of

Function Spaces
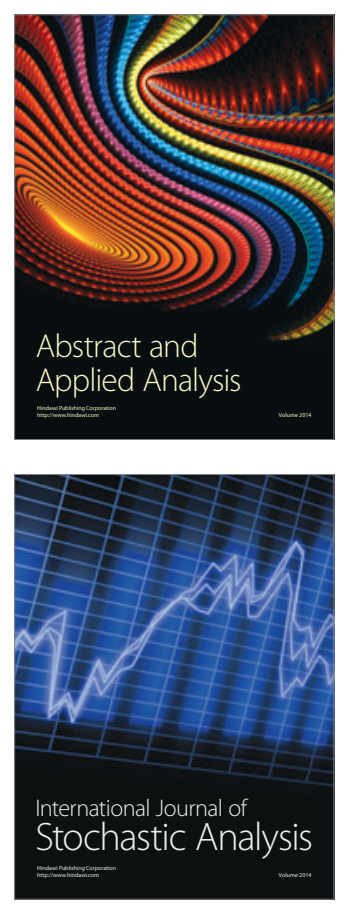

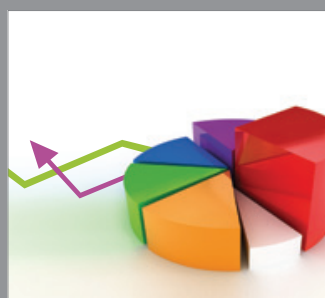

ournal of

Probability and Statistics

Promensencen
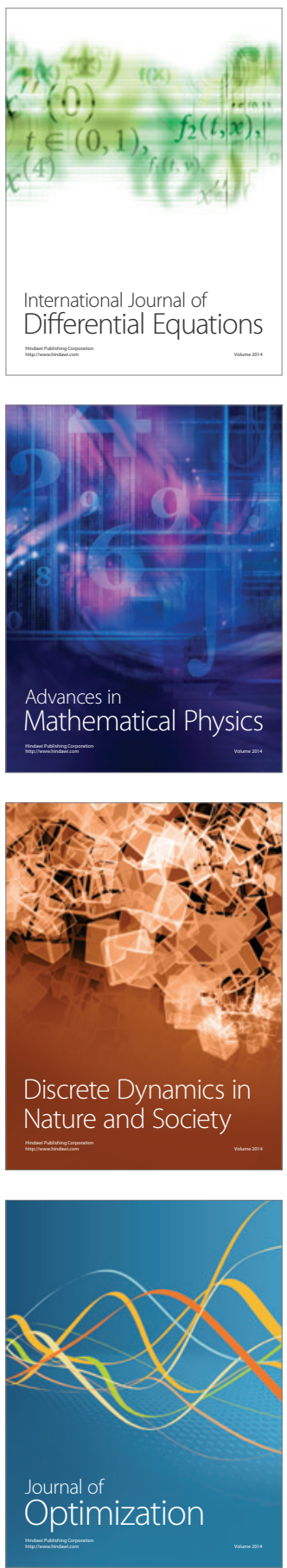